\title{
BMJ Open Mixed-method investigation of health consumers' perception and experience of participation in patient safety activities
}

\author{
Nam-Ju Lee (D) , ${ }^{1,2}$ Shinae Ahn (D) , ${ }^{1}$ Miseon Lee ${ }^{1}$
}

To cite: Lee N-J, Ahn S, Lee M. Mixed-method investigation of health consumers' perception and experience of participation in patient safety activities. BMJ Open 2020;10:e035831. doi:10.1136/ bmjopen-2019-035831

- Prepublication history and additional material for this paper are available online. To view these files, please visit the journal online (http://dx.doi. org/10.1136/bmjopen-2019035831).

Received 18 November 2019 Revised 11 February 2020 Accepted 14 February 2020

Check for updates

(C) Author(s) (or their employer(s)) 2020. Re-use permitted under CC BY-NC. No commercial re-use. See rights and permissions. Published by BMJ.

${ }^{1}$ College of Nursing, Seoul National University, Seoul, Republic of Korea

${ }^{2}$ The Research Institute of

Nursing Science, Seoul National University, Seoul, Republic of Korea

Correspondence to

Dr Shinae Ahn;

shinae.ahn17@gmail.com

\section{ABSTRACT}

Objectives This study aimed to examine the factors influencing patient safety behaviours and to explore health customers' experiences of patient participation in the healthcare system.

Design A mixed-method sequential explanatory design was employed using a survey and focus group interviews with health consumers.

Setting The study was conducted in South Korea using an online survey tool.

Participants Survey data were collected from 493 Korean adults, aged 19 years or older, who had visited hospitals within the most recent 1 year. Focus group interviews were conducted in two groups of six participants each among those of the survey participants who agreed to participate in focus groups.

Main outcome measures The survey measured the recognition of the importance of participation, extent of willingness to participate and experience of engaging in patient safety activities using a 4-point Likert scale. Qualitative data were collected through focus group interviews to explore health consumers' experience of patient participation in hospital care, and the data were analysed using content analysis.

Results The average score for experience of participation in patient safety behaviours $(2.13 \pm 0.63)$ was found to be lower than those of recognition of the importance of participation $(3.27 \pm 0.51)$ and willingness to participate (2.62 \pm 0.52$)$. By integrating the results of the quantitative and qualitative data analysis, the factors associated with the experience of engaging in healthcare behaviour included patient-related factors, illness-related factors, factors involving relationship between patients and healthcare providers, and healthcare environment factors. Conclusions To improve patient participation, it is necessary to create a healthcare environment in which patients can speak comfortably and to provide an education programme reflecting the patients' needs. Also, healthcare providers must consider patients as partners for patient safety. Shared decision-making procedures and patient-centred care and patient safety policies should be established in hospitals.

\section{INTRODUCTION}

Patient participation in healthcare is one strategy for improving patient safety. Patients

\section{Strengths and limitations of this study}

- This study was the first to examine patient participation in patient safety activities in South Korea and provided evidence on what factors affect actual patient safety activities using mixed methods.

- Most studies on patient participation have been descriptive studies, but this study performed a regression analysis and focus group interviews to identify factors that affect patient participation in patient safety activities, and finally, integrated the results of both quantitative and qualitative data.

- The results of this study can be used to develop the content of patient participation programmes and contribute to creating a patient-centred healthcare environment.

- The sample in this study was recruited through websites and social media, so the generalisability of the findings is limited.

who are more involved in their care tend to experience better health outcomes. Research shows that patients' taking an active role in their healthcare has positive impacts on patient safety, such as preventing errors, ${ }^{1}$ safer medication management, ${ }^{2}$ better selfmanagement behaviour ${ }^{3}$ and decreased use of healthcare services. ${ }^{4}$

The concept of patient participation is defined as the desire and capability to actively participate in care. ${ }^{5}$ To enhance patient participation for patient safety, it is important to encourage patients to participate in patient safety activities while receiving care in medical institutions. The safety activities that patients could participate in can be classified into four types (speaking up, asking questions, finding health information and engaging in the healthcare process). Patients can speak up if they have questions or concerns about their needs, preferences and ideas (eg, asking a healthcare provider whether they have washed their hands can contribute to a patient's safe treatment). ${ }^{67}$ Patients should 
ask questions and ask about their own health status if anything is unclear in their care process (eg, asking what the patient's health problem is), ${ }^{8}$ seek information about their care (eg, asking for resources and websites where patients can learn $)^{6}$ and participate in all decisions about their treatment through a shared decision-making process (eg, the patient sharing their needs, symptoms and wishes in order to make healthcare decisions together with their healthcare providers). ${ }^{89}$

Given the growing recognition and encouragement of patients' active role in healthcare, several international organisations have developed educational materials to increase patient participation to promote patient safety and quality of care. ${ }^{10-14}$ In the USA, the Agency for Healthcare Research and Quality has developed guidelines for patients to prevent errors and obtain safer care, ${ }^{12}$ the Joint Commission launched the Speak Up campaign to help patients and their family caregivers play active roles in care ${ }^{13}$ and the National Patient Safety Foundation has created a checklist of actions patients can take to reduce harm. ${ }^{14}$ The Canadian Patient Safety Institute in Canada has suggested strategies and evidence-based guidance on engaging patients in patient safety. ${ }^{6}$ Also, the Australian Commission on Safety and Quality in Health Care in Australia has developed a booklet to support patients being actively involved in their care. ${ }^{11}$

While the guidelines and materials for patients have been developed, there is a lack of evidence on the extent of patients' actual experience of participating in patient safety activities. Several studies have investigated patients' willingness to participate in safety-related behaviours by a quantitative method using surveys. ${ }^{15-17}$ However, these previous studies focused more on patients' inclination to perform safety practices, and there have been few studies on patients' actual participation experiences using quantitative data. One descriptive study assessing patients' experience in performing error-prevention behaviours while hospitalised showed that patients experienced asking general questions about the purpose of medication $(75.2 \%)$ and medical care $(85.1 \%)$ but had less experience asking healthcare providers about handwashing $(4.6 \%) .{ }^{18}$ Patients who are more comfortable engaging in safety-related behaviours are more likely to participate in safety activities. ${ }^{18}$

Moreover, gathering information on what factors affect patient participation is important. Some studies have described patients' perception of participation in patient safety by the qualitative method through interviews. ${ }^{19-21}$ Some factors were found to negatively affect patients' participation in their care, such as fear of reprisals from staff, an inability to provide feedback to staff and a perception that safety is generally not patients' priority. ${ }^{19}$ On the other hand, feeling connected with their healthcare provider, having an opportunity to provide feedback on experiences of safety and sharing responsibility positively affected patient participation. ${ }^{9-21}$ Evidence on these factors affecting patient participation can reduce the gap between the patients' intention and actual experience of patient participation in patient safety activities because intention does not necessarily lead to actual participation behaviours.

A mixed-method design has the advantage of producing a measure of experience of participation and deeply exploring patients' perspectives about patient participation. However, there is a lack of studies focusing on patient participation using mixed methods. To examine the factors influencing actual participation in various safety practices or to investigate the relationship between intention and actual behaviour, the need for a qualitative focus group interview or a mixed method using quantitative and qualitative approaches has been suggested. ${ }^{15} 16$

Thus, in this study, we investigated health consumers' recognition of the importance of their participation, their extent of willingness to participate in safety activities and their experience of participating in patient safety activities through a survey. We also explored healthcare consumers' experience of patient participation and factors influencing their experience of engaging in healthcare behaviours in depth.

\section{METHODS}

\section{Study design}

This study used a mixed-method sequential explanatory design including a survey and focus group interviews. According to this design proposed by Creswell and Zhang, ${ }^{22}$ we gathered and analysed quantitative data first, and then used qualitative data collection and analysed that qualitative data later to help explain the quantitative results.

\section{Participants and data collection}

To investigate health consumers' perception and experience of participation in patient safety activities, we conducted an online survey between 25 January and 3 February 2018, in South Korea. The target population comprised Korean-speaking Korean adults aged 19 years or older who had visited a medical institution within the most recent 1 year. We recruited participants through two websites, the Korea Alliance of Patients' Organizations (http://www.koreapatient.com/) and Resources for Enhancing Safety, Competency, and Utilization for Education (RESCUE, http:/ / patientsafety.snu.ac.kr/), as well as through social media. The websites are produced by non-profit organisations. The Korean Alliance of Patients' Organizations is a patient advocacy organisation that claims the rights of patients to prevent errors and create a patient-centred environment. RESCUE is a health information website that provides educational materials and resources for patient safety. The websites posted a description of the study and the link to the online survey. The survey was implemented using the Qualtrics online survey tool (https://www.qualtrics.com). A total of 493 participants completed the survey, and we excluded from the analysis the data of 1 respondent who reported being 18 years old (online supplementary figure 1 ). The total 
sample size exceeded the minimum of 103 required for multiple linear regression, based on Cohen's statistical method (significance level $\alpha=0.05,1-\beta=0.80$, effect size 0.15 , predictors 7 ).

We posted a description of the focus group interview on the website to recruit participants. Among the survey respondents, with those who agreed to participate in a focus group, focus group interviews were conducted 20-22 March 2018. The focus group interviews were conducted in two groups of six participants each, for 2 hours with each group in a seminar room at a university. We divided them to the two groups according to their availability, gender and ages. Each interview involved all of the researchers. Two researchers (N-JL or SA) of the research team each facilitated one of the focus group interviews, and one researcher (ML) played a role as a note taker to produce accurate notes while assisting with the focus groups. At the end of the interview, the interviewer summarised the conversation and repeated key information to request confirmation for data accuracy. The list of primary interview questions and safety activities in healthcare settings were sent to participants in advance to inform them on the areas of discussion to be covered. The key interview questions were as follows: 'What do you think about patient participation as it relates to patient safety?', 'In your opinion, how important is it to you to participate patient safety activities when you visit the hospital and receive medical care or treatment?', 'To what extent do you think you can participate in patient safety activities as a patient or their caregiver?', 'How do you think patient involvement in patient safety activities could affect patient safety?' and 'Can you tell us specifically about your experiences in which you participated in the care or treatment process?'

\section{Measures}

Patient participation was measured using a tool developed to measure the inclination to engage in patient safety practices. ${ }^{15}$ We added three items from the relevant literature ${ }^{182324}$ (bringing a friend or family member to a doctor's appointment; telling healthcare workers about any drug allergies; reporting errors to a national reporting system if they notice errors in the hospital). Thus, the final survey tool comprised 13 items, and the questions included a list of 13 specific safety-related behaviours through which patients can engage while undergoing care in medical institutions (online supplementary survey questionnaire). To explore the factors influencing patient participation, we grouped variables into the following three categories based on a literature review $^{15}{ }^{1823-25}$ : patient related (recognition of the importance of patient participation, willingness to participate and sociodemographic variables), illness related (number of visits to medical institutions and prior experience of patient safety incidents) and healthcare environment related (types of medical institutions).

Four-point Likert scales were used to assess the recognition of the importance of participation ( $1=$ not very important, 2=not important, $3=$ =important, $4=$ erery important) in patient safety activities and extent of health consumers' willingness to participate $(1=$ not at all, 2=somewhat likely, 3=likely, 4=very likely). Participants were asked to indicate how often they had experienced each patient safety activity in the hospital using a 4-point Likert scale ( $1=$ not at all, $2=$ sometimes, $3=$ often, $4=$ always). The reliability of the finalised questionnaire was evaluated using Cronbach's alpha coefficient. The Cronbach's alpha values of the three sections were 0.814 , 0.900 and 0.884 .

\section{Data analysis}

The quantitative data were analysed using SPSS V.24.0 (IBM Corp.). Participants' general characteristics and the scores of participants' recognition of the importance of participation, willingness to participate and participation experience were summarised using descriptive statistics. An independent t-test and one-way analysis of variance were used to identify differences in recognition of the importance of participation, willingness to participate and experience of patient participation by general characteristics. For correlations between recognition of the importance of participation, willingness to participate, and experience of participation, Pearson's correlation coefficients were used. Multiple linear regression analysis was performed to identify variables associated with experience of patient participation.

The qualitative data were analysed using conventional content analysis. ${ }^{26}$ All focus group interviews were recorded and transcribed. The collected data were written immediately after the interview, and the field notes were used for analysis. One researcher (SA) led the first analysis by reading the transcript repeatedly, and two researchers (N-JL and ML) performed a second review. Emergent themes were discussed in depth, then the researchers extracted codes, categories and themes together during content analysis until agreement was reached.

\section{Patient and public involvement}

Neither patients nor the public were involved in the design, development of the research questions, outcome measure or conduct of this study. To further facilitate the recruitment of patients, advertisements were posted on the websites.

\section{RESULTS}

\section{Participant characteristics}

A total of 492 completed surveys were included in the analysis. The mean age of the respondents was 31.7 years (SD 10.52), $74.8 \%$ of respondents were female, most had graduated from college or above $(n=373,75.8 \%)$ and most were unmarried $(n=310,63.0 \%)$. The monthly income of most participants $(\mathrm{n}=174,35.4 \%)$ was less than 850000 won. The most frequently visited medical institutions were clinics or public health centres $(n=343,69.7 \%)$, and more than $60 \%$ of the participants had visited medical 
institutions less than 10 times within the most recent 1 year. Most of the participants $(n=414,84.1 \%)$ reported going alone when they visited medical institutions, and $65 \%$ of the participants had experienced patient safety incidents. The vast majority of the participants $(n=483$, $98.2 \%$ ) did not know the fact that they could report patient safety incidents to the national reporting and learning system themselves (table 1).

\section{Participation in patient safety activities}

Among this study's findings on patient safety activities, average scores were as follows: recognition of the importance $(3.27 \pm 0.51)$, the extent of willingness $(2.62 \pm 0.52)$ and the experience of participation $(2.13 \pm 0.63)$. Respondents' experience of engaging in patient safety activities varied considerably. Some respondents reported that they always ask about the details of a procedure and the reason for a procedure before it is performed $(30.5 \%)$, ask for an explanation of care that they were not told about by their doctor or nurse $(22.0 \%)$ and call when they have not received the results of a medical test they underwent $(23.8 \%)$. Fewer respondents had the experience of asking healthcare workers if they had washed their hands $(2.7 \%)$, bringing a friend or family member to a doctor's appointment $(5.1 \%)$ or asking for healthcare workers to confirm patient identity before performing a procedure (6.3\%; table 2$)$.

The scores on recognising the importance of participation showed significant differences according to gender $(\mathrm{t}=-3.53, \mathrm{p}<0.001)$ and education level $(\mathrm{t}=-2.27$, $\mathrm{p}=0.024)$. The scores of respondents' willingness to participate differed significantly by education level $(\mathrm{t}=-2.19, \mathrm{p}=0.029)$, the type of accompanying caregivers $(\mathrm{F}=2.45, \mathrm{p}=0.045)$ and whether they had experienced patient safety incidents or not $(t=-2.19, p=0.029)$. The scores of participation experience differed significantly by gender $(t=-2.49, p=0.013)$, the type of medical institutions frequently visited $(\mathrm{F}=5.12, \mathrm{p}=0.002)$, the type of accompanying caregivers $(\mathrm{F}=3.29, \mathrm{p}=0.011)$ and previous experience of patient safety incidents $(\mathrm{t}=-3.34, \mathrm{p}=0.001$; table 3).

\section{Factors influencing experience of patient participation}

The respondents' experience of patient participation showed a significant positive correlation with recognition of the importance of participation $(\mathrm{r}=0.23, \mathrm{p}<0.001)$, and their willingness to participate $(\mathrm{r}=0.63, \mathrm{p}<0.001)$. In addition, participants' recognition of the importance of participation showed a significantly positive correlation with willingness to participate $(\mathrm{r}=0.34, \mathrm{p}<0.001)$.

Multiple linear regression was used to examine the relationship of the experience of patient participation with three sets of factors: patient related, illness related and healthcare environment related (table 4). The result of the multiple linear regression showed that the patient who frequently visited a hospital $(\beta=0.117, p=0.001)$ and a general or advanced general hospital $(\beta=0.077, p=0.035)$ rather than a clinic or public health centre, visited medical
Table 1 General characteristics of participants $(n=492)$

\begin{tabular}{|c|c|c|}
\hline Characteristics & Categories & $\mathbf{N}(\%)$ \\
\hline \multirow{4}{*}{$\begin{array}{l}\text { Age } \\
(\mathrm{M} \pm \mathrm{SD}, 31.72 \pm 10.52)\end{array}$} & $19-29$ & $270(54.9)$ \\
\hline & $30-39$ & $123(25.0)$ \\
\hline & $40-49$ & $57(11.6)$ \\
\hline & $50-$ & $42(8.5)$ \\
\hline \multirow[t]{2}{*}{ Gender } & Female & 368 (74.8) \\
\hline & Male & $124(25.2)$ \\
\hline \multirow[t]{2}{*}{ Educational level } & $\begin{array}{l}\text { High school diploma or } \\
\text { below }\end{array}$ & $119(24.2)$ \\
\hline & $\begin{array}{l}\text { Bachelor's degree or } \\
\text { above }\end{array}$ & $373(75.8)$ \\
\hline \multirow[t]{4}{*}{ Marital status } & Single & $310(63.0)$ \\
\hline & Married & $176(35.8)$ \\
\hline & Divorced & $5(1.0)$ \\
\hline & Bereaved & $1(0.2)$ \\
\hline \multirow{8}{*}{$\begin{array}{l}\text { Monthly income (Korean } \\
\text { won) }\end{array}$} & $-<850000$ & $174(35.4)$ \\
\hline & 850000 to $<1500000$ & $51(10.3)$ \\
\hline & 1500000 to $<2500000$ & $91(18.5)$ \\
\hline & 2500000 to $<3500000$ & $77(15.7)$ \\
\hline & 3500000 to $<4500000$ & $43(8.7)$ \\
\hline & 4500000 to $<5500000$ & $23(4.7)$ \\
\hline & 5500000 to $<6500000$ & $7(1.4)$ \\
\hline & $6500000-$ & $26(5.3)$ \\
\hline \multirow{4}{*}{$\begin{array}{l}\text { Types of medical } \\
\text { institutions frequently } \\
\text { visited }\end{array}$} & $\begin{array}{l}\text { Clinic or public health } \\
\text { centre }\end{array}$ & $343(69.7)$ \\
\hline & Hospital & $68(13.8)$ \\
\hline & $\begin{array}{l}\text { General or advanced } \\
\text { general hospital }\end{array}$ & $79(16.1)$ \\
\hline & Others & $2(0.4)$ \\
\hline \multirow{6}{*}{$\begin{array}{l}\text { Number of visits to } \\
\text { medical institutions }\end{array}$} & $-<5$ & 165 (33.5) \\
\hline & 5 to $<10$ & $176(35.8)$ \\
\hline & 10 to $<15$ & $80(16.3)$ \\
\hline & 15 to $<20$ & $40(8.1)$ \\
\hline & 20 to $<25$ & $15(3.0)$ \\
\hline & $25-$ & $16(3.3)$ \\
\hline \multirow{5}{*}{$\begin{array}{l}\text { Types of accompanying } \\
\text { caregivers }\end{array}$} & Alone & $414(84.1)$ \\
\hline & Spouse & $19(3.9)$ \\
\hline & Children & $23(4.7)$ \\
\hline & $\begin{array}{l}\text { Parents (father or } \\
\text { mother) }\end{array}$ & $31(6.3)$ \\
\hline & Others & $5(1.0)$ \\
\hline \multirow{2}{*}{$\begin{array}{l}\text { Experience of patient } \\
\text { safety incidents }\end{array}$} & Yes & $320(65.0)$ \\
\hline & No & $172(35.0)$ \\
\hline \multirow{2}{*}{$\begin{array}{l}\text { Do you know the fact } \\
\text { that you can directly } \\
\text { report to the patient } \\
\text { safety reporting and } \\
\text { learning system? }\end{array}$} & Yes & $9(1.8)$ \\
\hline & No & $483(98.2)$ \\
\hline
\end{tabular}




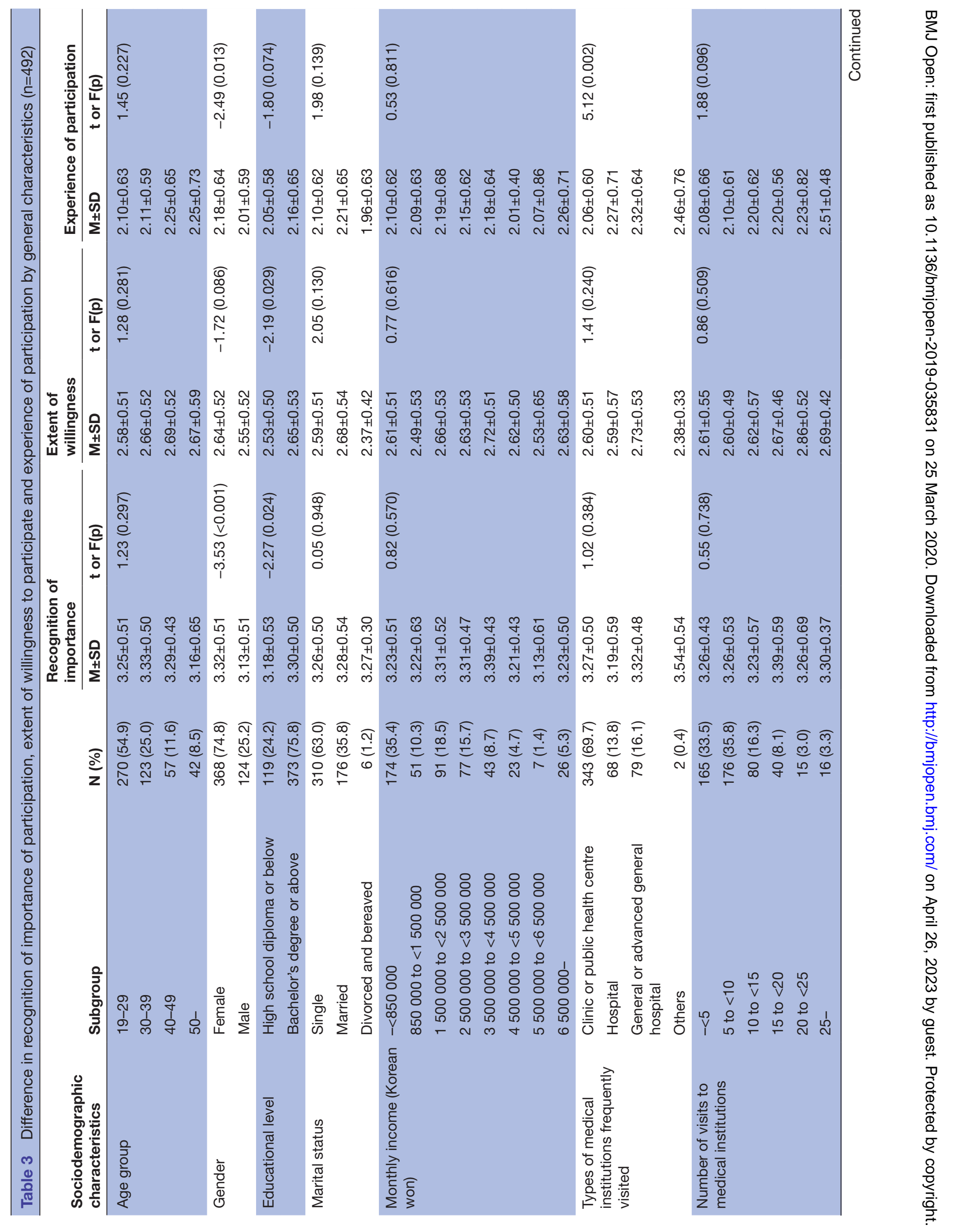




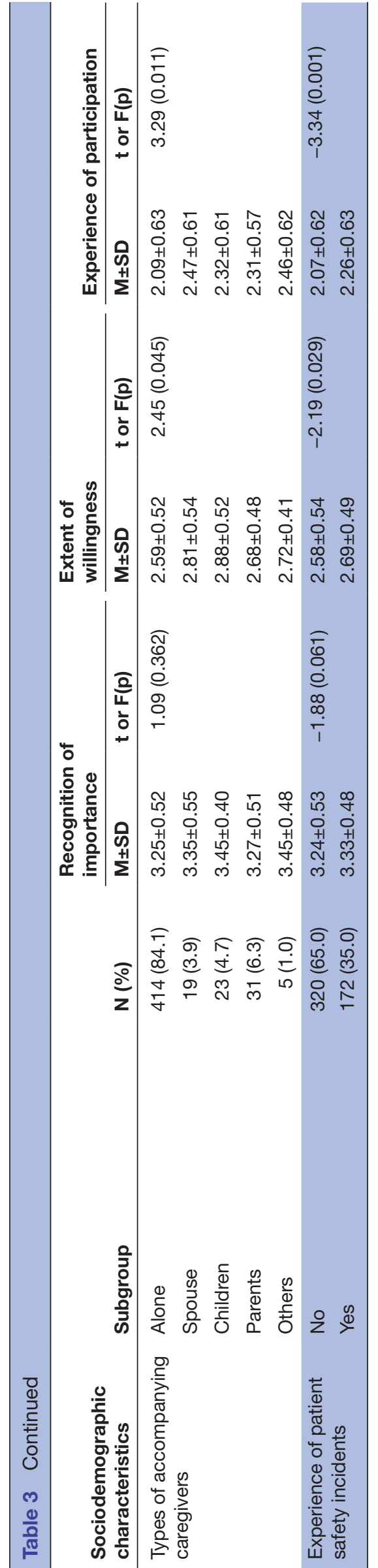

Table 4 Factors influencing the experience of patient participation $(n=492)$

\begin{tabular}{|c|c|c|c|}
\hline Variables & Beta & $\mathbf{t}$ & P value \\
\hline (Constant) & & -0.110 & 0.913 \\
\hline $\begin{array}{l}\text { Recognition of importance of } \\
\text { patient participation }\end{array}$ & 0.020 & 0.527 & 0.595 \\
\hline Willingness to participate & 0.600 & 16.413 & $<0.001$ \\
\hline \multicolumn{4}{|l|}{ Gender } \\
\hline Male & Ref. & & \\
\hline Female & 0.037 & 1.021 & 0.308 \\
\hline \multicolumn{4}{|l|}{ Types of accompanying caregivers } \\
\hline Alone & Ref. & & \\
\hline Spouse & 0.062 & 1.766 & 0.078 \\
\hline Children & 0.008 & 0.218 & 0.827 \\
\hline Parent & 0.025 & 0.691 & 0.490 \\
\hline Others & 0.035 & 0.992 & 0.322 \\
\hline \multicolumn{4}{|c|}{ Number of visits to medical institutions in last year } \\
\hline$-<5$ & Ref. & & \\
\hline 5 to $<10$ & 0.024 & 0.611 & 0.542 \\
\hline 10 to $<15$ & 0.058 & 1.493 & 0.136 \\
\hline 15 to $<20$ & 0.018 & 0.492 & 0.623 \\
\hline 20 to $<25$ & -0.003 & -0.072 & 0.942 \\
\hline $25-$ & 0.095 & 2.498 & 0.013 \\
\hline \multicolumn{4}{|c|}{ Experience of patient safety incidents } \\
\hline No & Ref. & & \\
\hline Yes & 0.065 & 1.849 & 0.065 \\
\hline \multicolumn{4}{|c|}{ Medical institutions frequently visited } \\
\hline Clinic or public health centre & Ref. & & \\
\hline Hospital & 0.117 & 3.287 & 0.001 \\
\hline $\begin{array}{l}\text { General or advanced general } \\
\text { hospital }\end{array}$ & 0.077 & 2.113 & 0.035 \\
\hline Others & 0.019 & 0.525 & 0.600 \\
\hline
\end{tabular}

$F=23.19(p<0.001)$; Adjusted $R^{2}=0.42$.

institutions more than 25 times in the most recent 1 year ( $\beta=0.095, p=0.013)$ rather than less than five times, and had a high score on willingness to participate $(\beta=0.600$, $\mathrm{p}<0.001$ ) was expected to have more experience of participating in patient safety activities.

Focus group interviews: health consumers' experience of patient participation in hospital care

Twelve health consumers participated in the interview. Four interviewees were male and eight were female. The average age was 40 years (range 29-55 years). Ten interviewees had visited medical institutions more than five times in last year and six interviewees had experienced patient safety incidents. Content analysis produced five categories extracted under three themes (table 5).

The results of the focus group interviews showed that patient participation in medical institutions appeared to be influenced by three types of factors: patient-related 
Table 5 Themes, categories and codes

\begin{tabular}{lll} 
Theme & Category & Code \\
\hline $\begin{array}{l}\text { Patient-related } \\
\text { factors }\end{array}$ & $\begin{array}{l}\text { Willingness and } \\
\text { motivation }\end{array}$ & $\begin{array}{l}\text { Perception of the } \\
\text { importance of patient } \\
\text { participation }\end{array}$
\end{tabular}

\section{Quotes}

The treatment outcome seems to be different depending on whether I participated in patient safety activities or not. (Participant 2, Group 1) As soon as I realize I am speaking up and participating in my care, I feel that I'm an active patient. That changes the degree of participation. (Participant 1, Group 1)

Accompanied by caregiver My grandfather went to several hospitals and took medications from those hospitals which were the same medications he'd gotten from his primary hospital. He had no idea there were duplicates and took them all...After that I told him to get a paper prescription from the pharmacy and to bring medications which he got from other hospitals when he visits his primary hospital. I know that older people need to be accompanied by a family member when they go to the hospital. (Participant 1, Group 1) In medical settings, I thought that patient and family participation in the care process as a member of a healthcare team is important. Since my family could be anyone, a patient or a healthcare provider, I thought patient and family participation is necessary. (Participant 2, Group 2)

Previous experience of a patient safety incident

I really wanted to hear: "Sorry, we made a mistake with the medication for your daughter. So, we took this kind of action after the incident." But they didn't apologize and didn't take any follow-up action. After this incident, I strongly realized the importance of patient safety and the family's participation. (Participant 6, Group 2)

Concerns about having any Foremost, I'm afraid of having any disadvantage on my treatment, like disadvantages in treatment snubbing me after I ask questions. (Participant 6, Group 2)

I had a feeling on that he doesn't put an effort into, or pay attention during my treatment. (Participant 4, Group 2)

The dentist always doesn't wash his hands. But I've already done my orthodontics and if I move to another dentist, it costs more. If I pointed out that he didn't wash his hands, I thought I would be disadvantaged, so I think I've never been able to tell him. (Participant 3, Group 1)

Knowledge and Level of health literacy and skill extent of knowledge

When I asked my doctor about my medication, "I've heard there is this certain drug. Why didn't you prescribe this drug for me before?" And he replied, "The other one that I prescribed is better for your hormone levels." I couldn't understand what he said after that, so I couldn't ask more. (Participant 1 , Group 1)

He just explained in terms that he was used to. So, I had no idea about the terminology, if it was a diaphragm or something else. (Participant 6, Group 1) If I took the drug, my skin became thinner when taking a high dose of an anticancer drug. There were too many side effects. I felt outraged and became sad. "What a fool I am. I should have spoken up." Or I could have asked about the medication at another hospital. But the medical field is too professional for me. So I had no choice but to trust him. (Participant 2, Group 2)

Educational needs to participate in their care process

I need information on what I can do and check specifically depending on the situation. (Participant 2, Group 2)

I think it would be nice if I could get an app that suggests a potential diagnosis after inputting my age and symptoms and so on. Because I can ask a doctor, "In my opinion, my symptom is A, isn't it?" A doctor may miss the exact diagnosis owing to being busy, right? So, in that case, if I know the information on my symptoms and talk to him, then he can consider the diagnosis and go forward with his treatment plan in the right direction. (Participant 2, Group 1) When I get the medicine at the pharmacy, the information about that medicine is written on the medicine packet, and I think this is very useful for patients. (Participant 2, Group 2)

I think it's pretty important to know what questions I can ask. If I have a list of things to look out for and check, it is easy for me to get more involved. (Participant 4, Group 1) I want to know what kinds of rights patients have. (Participant 6, Group 2)

Continued 
Table 5 Continued

$\begin{array}{llll}\text { Theme } & \text { Category } & \text { Code } & \text { Quotes } \\ \text { Factors } & \text { Supportive } & \text { Attention on a patient and } & \text { One doctor abrasively listened to me, not my father-in-law, because he }\end{array}$

\section{Factors} involving the relationship

between

patients and

healthcare

providers relationships endeavour to communicate
No opportunity Hierarchical relationship to participate between the patient and healthcare provider

Lack of communication between healthcare provider and the patient

Failure to share treatment plan with the patient

couldn't communicate well, and gave only a routine prescription. On the other hand, another doctor tried to talk directly to my father-in-law in detail, and then, to verify, asked me, "He seemed to express such-and-such. Did you find he had the same symptoms at home?" and explained his conclusions to me in detail. I was able to trust that doctor more. (Participant 1, Group 1) When the nurse simply said, "A certain virus was found. When are you available for your next appointment?", I was so worried because I had no idea what the virus was. So I asked the nurse to explain about the virus, and the nurse was willing to answer all of my questions. (Participant 1, Group 2)

When I asked what I didn't understand one more time, the doctor responded with a high and angry tone. After experiencing that, although I didn't catch what he said, I didn't ask him and instead asked another healthcare provider because I already knew what his response would be if I asked again. (Participant 3, Group 2)

I had a surgery for ovarian tumor removal. My doctor briefly explained that I could choose either laparoscopic surgery or laparotomy. And I was moved to the next room to schedule the surgery. The other doctor told me in the room that "even though laparoscopic surgery is covered by insurance, it is a little more expensive, while laparotomy is cheap." He just explained it this way. (Participant 1, Group 1)

I haven't felt that I was able to fully ask questions or get satisfactory answers. (Participant 6, Group 1)

In the process of my treatment, I didn't feel a sense of care from any doctor or nurse. This is because they only checked over my data and wrote prescriptions, and asked about my current physical state. I had the same experience over and over. (Participant 4, Group 2)

I asked my doctor what the care plan was. Then the doctor firmly said, rather than sharing the future treatment plan, "Do you want to go to another hospital?" (Participant 5, Group 2)

When I try to give my opinion to try to participate from the patient's position, whether it is right or wrong...There are doctors who insist unconditionally, saying "No, the treatment that I am doing is right." In this case, I am not able to say anything, and I am no longer willing to participate. (Participant 2, Group 1)

\begin{tabular}{|c|c|c|c|}
\hline \multirow[t]{2}{*}{$\begin{array}{l}\text { Healthcare } \\
\text { environment } \\
\text { factors }\end{array}$} & \multirow[t]{2}{*}{$\begin{array}{l}\text { Complexity of } \\
\text { the healthcare } \\
\text { environment }\end{array}$} & Complex care procedures & $\begin{array}{l}\text { It was exhausting for a patient to meet a new healthcare provider every } 2 \text { or } 3 \\
\text { min, and it was hard for me to share my problems deliberately. When talking to } \\
\text { the final healthcare provider, a chief surgeon who was charge of my surgery, I } \\
\text { was very fatigued so I couldn't think of what to say. (Participant 1, Group 1) }\end{array}$ \\
\hline & & $\begin{array}{l}\text { Difference in patient } \\
\text { participation by type of } \\
\text { medical institutions }\end{array}$ & $\begin{array}{l}\text { When I visit an advanced hospital for surgery or another examination, people } \\
\text { who work there don't know about me. So I started to write down details such } \\
\text { as when I was ill or where I had pain, and brought it with me before someone } \\
\text { asked me about it. (Participant 5, Group 1) } \\
\text { When I visited an advanced hospital, they gave me information about what } \\
\text { drug it was and what side effect it had. However, the clinic did not give me this } \\
\text { information. (Participant 3, Group 2) }\end{array}$ \\
\hline
\end{tabular}

factors, factors involving the relationship between patients and healthcare providers, and healthcare environment factors.

\section{Patient-related factors}

Some focus group members reported that patient participation in their care process resulted in a different treatment outcome. The participants were actively involved in their care process through patient safety behaviours such as asking for information. Going to the hospital with family members was a motivating factor for patient participation. Their family members helped patients to ask questions, check their prescriptions and remind them of what they should say to the doctor. In addition, participants reported that their previous experience of a patient safety incident and their perception of the importance of patient safety activities made them more active patients. However, the participants were worried about having any 
disadvantages in their care if they pointed out healthcare providers' behaviours which could threaten patient safety. This undermined their willingness to participate.

In order to understand the purpose of treatment and actively engage in their treatment process while being in the hospital, they emphasised the need to know what is going on.

However, they did not have enough knowledge about their healthcare and felt it was difficult to understand their care process, including their medication, diagnosis and treatment plan. Therefore, they could not share in the development of the treatment plan with their healthcare providers. Participants thought it was important to understand their healthcare by being informed about what patients have to do or what patients can do. There were various topics on which participants wanted to be educated such as disease, diagnosis, treatment, examination and medication. Participants also thought it was important for patients to know what questions should be asked.

Factors involving the relationship between patients and healthcare providers

In order to participate in patient safety activities in the care process, it was important that patients establish a supportive relationship with healthcare providers. Explaining the details of treatment, listening to patients and paying attention to patients were important factors for promoting patient participation.

On the other hand, a hierarchy existed between doctors and patients. Focus group members mentioned that they felt they had not received satisfactory explanations from healthcare professionals, but they also felt they could not ask a follow-up or repeat question, even if they wanted to. When a patient asked a doctor a question, the doctor was often annoyed and did not explain or share his or her treatment plan. Focus group participants reported that their hesitation to participate was also related to this hierarchical relationship between patients and healthcare providers.

\section{Healthcare environment factors}

All participants stated that the processes and procedures for receiving care were very complex in hospitals, and the time allocated to see a doctor for treatment and care was very limited. Also, the type of healthcare delivery system, such as clinic or advanced hospital, affected the patients' willingness to participate in patient safety activities. Participants were more prepared with their health information when they visited a higher level of medical institution, and they also received more information from the medical institution.

By integrating the results of the quantitative and qualitative data analysis, this study showed that the factors influencing patient participation in medical institutions could be categorised into four factors: patient-related factors, illness-related factors, factors involving the relationship between patients and healthcare providers, and healthcare environment factors.

\section{DISCUSSION}

This is the first study to investigate patient participation in patient safety activities in South Korea from the health consumer's viewpoint. This study provided evidence on what factors affect actual patient safety behaviours.

This study found that the average score for experience of participation in patient safety behaviours was lower than those of recognition of the importance of participation and willingness to participate. The frequency of health consumers' experience of participation in patient safety activities varied considerably. Among patient safety activities, the most frequently performed were asking general questions such as the details of surgery' and 'an explanation of what the patient does not understand'. On the other hand, 'asking healthcare workers to wash their hands' was the patient safety behaviour with the lowest average scores for intention and experience. These results were consistent with previous findings. ${ }^{15}$ Specifically, asking healthcare workers wash their hands has been considered a challenging behaviour, ${ }^{16}$ with various potential explanations proposed in previous research. Patients themselves felt uncomfortable with asking about handwashing, ${ }^{18}$ and they were worried that healthcare workers might feel uncomfortable with this question. ${ }^{16}$ In addition, patients thought that questioning healthcare providers about their behaviour could imply criticising their incompetence, and therefore they were reluctant to do so. ${ }^{15}$ In the qualitative interview of our study, we learnt that patients worried about encountering any disadvantages in treatment if they were to question a healthcare provider when they found something were not right. These findings might reflect that patients prefer to passively participate in their care, but it also might be related to the healthcare environment where patients cannot actively communicate or raise questions and concerns with their clinicians.

The relationships among patients' perception of importance, their willingness and their experience of patient participation were found to correlate in the quantitative results of this study. Likewise, the qualitative results showed that the perception of the importance of patient participation increased willingness and experience of patient participation. This finding is consistent with a previous study that explored barriers and facilitators to patient involvement in reporting safety experiences within care transfer. ${ }^{19}$ When patients conceptualised patient safety, they were likely to provide feedback on safety experiences. ${ }^{19}$ Patients who perceived that patient safety was not their responsibility preferred to adopt a passive role in their care. ${ }^{19} 2728$

Our study found that patients' extent of knowledge on healthcare was an important influence on patient participation in safety activities. Patient education can help to increase patients' knowledge related to their health and positively affect their attitude toward safety practices. ${ }^{29}$ Therefore, healthcare providers must consider developing and implementing effective education for patients. When 
healthcare providers develop education programmes or strategies to improve patient participation, a patient's abilities, needs and preferences for participation must be taken into consideration. ${ }^{30}$ In this study's findings, health consumers wanted education programmes focusing on 'a question list they can ask health professionals', 'patient rights and responsibilities', and 'a variety of information related to treatment including disease and diagnosis, and medication'. Thus, our study's findings suggest developing an education programme reflecting these educational needs.

The quantitative and qualitative results of this study showed that patients with caregivers had more willingness and motivation to participate in patient safety and were more involved in patient safety activities than unaccompanied patients were. Increased patient and family engagement is associated with improved patient outcomes and reduced utilisation of healthcare services, ${ }^{31}{ }^{32}$ and it is recommended that medical institutions also encourage patients and their family members to participate in safety activities. This could be a way of increasing the overall frequency of actual patient safety activities and that of specific activities like 'bringing a friend or family member to a doctor's appointment' in medical institutions.

Most patients felt that the relationship between patients and healthcare providers was hierarchical, which was one of the barriers to participation. According to a previous intervention study that developed a prototype consumer reporting system for medical errors, the contributing factors of medical mistakes included problems with communication and staff responsiveness to patients. ${ }^{33}$ However, patients can be motivated to participate in patient safety activities through open communication with, positive feedback from and supportive relationships with healthcare providers. According to Maurer et $a l,{ }^{34}$ healthcare providers' negative reactions can be a barrier to patient participation, while their active invitation for patients to participate can be a facilitator. Thus, healthcare providers must support and guide patients to participate. Even if patients are willing to participate in safety activities, they might be uncertain about how to be involved. It is important that healthcare providers consider patients as partners for patient safety ${ }^{35}$ and encourage them to speak up if they have a concern. However, according to Fisher et al, nearly half of patients $(48.6 \%)$ in their study had experienced a problem during hospitalisation, and almost one-third $(30.5 \%)$ of them reported they were not always comfortable speaking up. ${ }^{36}$ Creating a healthcare environment in which patients can be comfortable raising their concerns may result in safer care and improved patient participation. ${ }^{36}$

The findings of our study showed that the frequency of visiting medical institutions affected the experience of patient participation. According to Davis et al, ${ }^{25}$ severity of the patients' illness, symptoms and treatment plan were associated with patient participation. In addition, patients' prior experience of illness led to more willingness to participate. ${ }^{25}$ This may be due to the fact that patients with more experience of visiting medical institutions may have more severe illness and will be likely to be exposed to higher risk situations such as testing, drugs and surgery, all of which call for patient safety activities. It can also be inferred that patients who have experienced many hospital visits might perceive themselves as playing a more important role in the care process. Our study showed that over $60 \%$ of participants had visited medical institutions less than 10 times within the most recent 1 year. According to the national data reported by National Health Insurance Statistics, ${ }^{37}$ the annual number of outpatient visits to medical institutions per capita is 17.72 , which is calculated by dividing the number of outpatient visits of all citizens (health insurance patients) by the average annual population covered by health insurance. Considering this statistic, the participants of our study may be a relatively healthy population, so these characteristics of the participants may have affected the outcomes in this study. Therefore, further research is needed to examine the factors influencing experience of participation including diverse patients' illness-related characteristics such as health status and prior experience of illness.

A complex care process, time constraints and different types of healthcare delivery systems were healthcare environmental factors influencing patient participation. A qualitative study conducted with patients and nursing staff members found similar results-that patients felt that healthcare providers were too busy asking questions or talking. ${ }^{20}$ Patients and families may feel overwhelmed by the healthcare system and highly technical information. ${ }^{34} 38$ Therefore, the organisational context within hospitals, including workflow processes and hospital polices, should be changed to be focused on patient-centred care and patient safety. Then, a culture of safety should be established in hospitals.

This study had several limitations. First, the study was based on health consumers' self-reports on their participation in patient safety practices, so these self-reported data may not accurately reflect their actual practices in medical institutions. Second, convenience sampling was used to generate the sample, and was drawn from only two websites plus social media, so people who do not regularly use computers or social network services might not have participated in this study. Therefore, the young, relatively healthy and well-educated population might have accounted for a large proportion of the sample. Thus, it may not be generalisable to all patient groups. Future research is suggested to investigate the experience of participation using national data through a systematic sampling design.

\section{CONCLUSION}

There were differences among patients' perceived importance of their participation, willingness to participate and their actual experience of participation in patient safety activities. Future research needs to be conducted to 
narrow these gaps using efficient educational methods. Our study suggests that an education programme should be developed that reflects patients' educational needs, such as lists of questions and information on patient safety activities. The results of this study can be used as a reference for developing educational content for patients. Also, the findings from our study may be useful for updating patient participation guidelines.

Healthcare providers may play an important role in encouraging patients to involve themselves in patient safety practices by offering education and encouragement to patients. Strategies are needed to give participation opportunities to patients during their care. Shared decision-making procedures and patient-centred policies should be made to create a healthcare environment in which patients and healthcare providers can participate together to improve patient safety.

Contributors N-JL and SA conceived and designed the study and carried out the statistical analysis. All authors performed the cross-sectional study; conducted qualitative research; wrote the paper; reviewed and edited the manuscript; read and approved the manuscript.

Funding This work was supported by the Basic Science Research Programme through the National Research Foundation of Korea (2017R1D1A1B03034406).

Competing interests None declared.

Patient consent for publication Not required.

Ethics approval This study was approved by the Institute Review Board of Seoul National University (No. 1801/003-007) and all study participants provided informed consent.

Provenance and peer review Not commissioned; externally peer reviewed.

Data availability statement № data are available.

Open access This is an open access article distributed in accordance with the Creative Commons Attribution Non Commercial (CC BY-NC 4.0) license, which permits others to distribute, remix, adapt, build upon this work non-commercially, and license their derivative works on different terms, provided the original work is properly cited, appropriate credit is given, any changes made indicated, and the use is non-commercial. See: http://creativecommons.org/licenses/by-nc/4.0/.

\section{ORCID iDs}

Nam-Ju Lee http://orcid.org/0000-0003-0453-4088

Shinae Ahn http://orcid.org/0000-0002-5014-3021

\section{REFERENCES}

1 Weingart SN, Zhu J, Chiappetta L, et al. Hospitalized patients' participation and its impact on quality of care and patient safety. Int $J$ Qual Health Care 2011;23:269-77.

2 Hall J, Peat M, Birks Y, et al. Effectiveness of interventions designed to promote patient involvement to enhance safety: a systematic review. Qual Saf Health Care 2010;19:e10.

3 Hibbard JH, Mahoney ER, Stock R, et al. Do increases in patient activation result in improved self-management behaviors? Health Serv Res 2007;42:1443-63.

4 Bertakis KD, Azari R. Patient-Centered care is associated with decreased health care utilization. J Am Board Fam Med 2011;24:229-39.

5 Higgins T, Larson E, Schnall R. Unraveling the meaning of patient engagement: a concept analysis. Patient Educ Couns 2017;100:30-6.

6 Canadian Patient Safety Institute. Engaging patients in patient safety - a Canadian guide, 2017. Available: www.patientsafetyinstitute.ca/ engagingpatients

7 The Joint Commission. Speak Up campaigns, 2002. Available: https://www.jointcommission.org/resources/for-consumers/speakup-campaigns/
8 Manitoba Institute for Patient Safety. Self-Advocacy for everyone (safe) toolkit, 2011. Available: http://www.safetoask.ca/s.a.f.e.-toolkit. html

9 Davis RE, Pinto A, Sevdalis N, et al. Patients' and health care professionals' attitudes towards the pink patient safety video. J Eval Clin Pract 2012;18:848-53.

10 World Health Organization. Exploring patient participation in reducing health-care-related safety risks, 2013. Available: http://www.euro. who.int/en/publications/abstracts/exploring-patient-participation-inreducing-health-care-related-safety-risks

11 Australian Commission on Safety and Quality in Health Care. Top tips for safe health care, 2017. Available: https://www.safetyandquality. gov.au/publications-and-resources/resource-library/top-tips-safehealth-care

12 Agency for Healthcare Research and Quality. 20 tips to help prevent medical errors: patient fact sheet, 2011. Available: https://www. ahrq.gov/patients-consumers/care-planning/errors/20tips/index. html

13 The Joint Commission. Speak Up TM about your care, 2019. Available: https://www.jointcommission.org/resources/for-consumers/speakup-campaigns/about-your-care/

14 National Patient Safety Foundation. What should patients do to help make care safe? 2016

15 Marella WM, Finley E, Thomas AD, et al. Health care consumers' inclination to engage in selected patient safety practices: a survey of adults in Pennsylvania. J Patient Saf 2007;3:184-9.

16 Davis RE, Sevdalis N, Vincent CA. Patient involvement in patient safety: how willing are patients to participate? BMJ Qual Saf 2011:20:108-14.

17 Davis RE, Koutantji M, Vincent CA. How willing are patients to question healthcare staff on issues related to the quality and safety of their healthcare? an exploratory study. Qual Saf Health Care 2008;17:90-6.

18 Waterman AD, Gallagher TH, Garbutt J, et al. Brief report: hospitalized patients' attitudes about and participation in error prevention. J Gen Intern Med 2006;21:367-70.

19 De Brún A, Heavey E, Waring J, et al. PReSaFe: a model of barriers and facilitators to patients providing feedback on experiences of safety. Health Expect 2017;20:771-8.

20 Bishop AC, Macdonald M. Patient involvement in patient safety: a qualitative study of nursing staff and patient perceptions. J Patient Saf 2017:13:82-7.

21 Hrisos S, Thomson R. Seeing it from both sides: do approaches to involving patients in improving their safety risk damaging the trust between patients and healthcare professionals? an interview study. PLoS One 2013;8:e80759.

22 Creswell JW, Zhang W. The application of mixed methods designs to trauma research. J Trauma Stress 2009;22:612-21.

23 Kaiser Family Foundation, Agency for Healthcare Research and Quality. 2006 update on consumers' views of patient safety and quality information, 2006. Available: https://psnet.ahrq.gov/ resources/resource/4394/2006-Update-on-Consumers-Views-ofPatient-Safety-and-Quality Information-?q=2006+Update+on+Consu mersViews+of+Patient+Safety+and+Quality+Information

24 Davis RE, Vincent C, Sevdalis N. Predictors of patients' intentions to participate in incident reporting and medication safety. J Patient Saf 2015;11:191-7.

25 Davis RE, Jacklin R, Sevdalis N, et al. Patient involvement in patient safety: what factors influence patient participation and engagement? Health Expect 2007;10:259-67.

26 Hsieh H-F, Shannon SE. Three approaches to qualitative content analysis. Qual Health Res 2005;15:1277-88.

27 Rathert C, Huddleston N, Pak Y. Acute care patients discuss the patient role in patient safety. Health Care Manage Rev 2011;36:134-44.

28 Heavey E, Waring J, De Brún A, et al. Patients' Conceptualizations of responsibility for healthcare: a typology for understanding differing Attributions in the context of patient safety. J Health Soc Behav 2019;60:188-203.

29 An J, Kim SJ, Park S, et al. The effects of patient education on patient safety: can we change patient perceptions and attitudes?: lessons from the armed forces capital hospital in Korea. Int J Qual Health Care 2017;29:392-8.

30 Kolovos P, Kaitelidou D, Lemonidou C, et al. Patient participation in hospital care: nursing staffs' point of view. Int $J$ Nurs Pract 2015;21:258-68.

31 Herrin J, Harris KG, Kenward K, et al. Patient and family engagement: a survey of US Hospital practices. BMJ Qual Saf 2016;25:182-9.

32 Etchegaray JM, Ottosen MJ, Aigbe A, et al. Patients as partners in learning from unexpected events. Health Serv Res 2016;51 Suppl 3:2600-14. 
33 Weingart SN, Weissman JS, Zimmer KP, et al. Implementation and evaluation of a prototype consumer reporting system for patient safety events. Int J Qual Health Care 2017;29:521-6.

34 Maurer M, Dardess P, Carman KL, et al. Guide to patient and family engagement: environmental scan report. Rockville, MD: Agency for Healthcare Research and Quality, 2012.

35 Sahlström M, Partanen P, Rathert C, et al. Patient participation in patient safety still missing: patient safety experts' views. Int $J$ Nurs Pract 2016;22:461-9.
36 Fisher KA, Smith KM, Gallagher TH, et al. We want to know: patient comfort speaking up about breakdowns in care and patient experience. BMJ Qual Saf 2019;28:190-7.

37 Statistics Korea. National health insurance statistics, 2018. Available: https://www.index.go.kr/unify/idx-info.do?idxCd=4240\& clas $\mathrm{Cd}=7$

38 MacKean GL, Thurston WE, Scott CM. Bridging the divide between families and health professionals' perspectives on family-centred care. Health Expect 2005;8:74-85. 